\title{
Net energy value of rapeseed oil infused into the duodenum of lactating cows
}

\author{
M Vermorel1, Y Chilliard², J Vernet' ${ }^{1}, \mathrm{D}$ Bauchart ${ }^{1}$, A Ollier² \\ with the technical assistance of $Y$ Anglaret, $F$ Duboisset, $S$ Gasnet, \\ C Legay, C Leoty, R Souchet \\ 1 Laboratoire d'Etude du Métabolisme Energétique; \\ 2 Laboratoire de la Lactation, INRA, Theix, 63122 St-Genes Champanelle, France
}

Fat is increasingly used in dairy cow feeding to reduce energy deficiency during early lactation. However, its net energy value (NE) is not yet accurately known because of the low levels of fat used and because of digestive interaction with other food components (Vermorel et al, 1986).

Five dairy cows fitted with duodenal cannula were fed ad lib a $60 \%$ corn silage and $40 \%$ concentrate diet. They followed a cross-over design, with (O diet) or without (C diet) rapeseed oil. Oil $(1000 \mathrm{~g} / \mathrm{d})$ was continuously infused into the duodenum for 4 wk after the lactation peak. Feces and urine were collected over $6 \mathrm{~d}$ periods after 3 wk of adaptation. The lipids and fatty acids of feeds and feces were determined gravimetrically. Heat production was measured by indirect calorimetry for $4 \mathrm{~d}$.

Milk production averaged $24.6 \mathrm{~kg}$ fatcorrected milk (FCM)/d with both diets and gross energy intake (including oil) 341 ( $s=$ $45)$ and $318(s=25) \mathrm{MJ} / \mathrm{d}$ in groups $\mathrm{C}$ and $O$, respectively. Energy digestibility was $71.7 \%(s=1.8)$ and $68.8 \%(s=1.6)(P<$ $0.10)$, lipid digestibility $67.1 \%(s=2.1)$ and $56.8 \%(s=5.8)(P<0.05)$ and fatty acid digestibility $67.5 \%(s=1.6)$ and $70.3 \%(s$ $=4.8$ ) (NS) for the diets $C$ and $O$, respectively. Lipid and fatty acid intestinal digestibility of oil were calculated by difference to be $50.8 \%(s=9.7)$ and $71.2 \%(s=6.2)$.
Energy gain was calculated as the mean of the respiratory quotient (RQ) and carbon-nitrogen (CN) balances. The efficiency ( $k l)$ of metabolizable energy (ME) utilization was computed by assuming that the maintenance requirement of lactating cows was $293 \mathrm{~kJ} N E L / \mathrm{kg}$ BW0.75. It was higher for the $O$ than for the $C$ diet: $60.8 \%$ $(s=3.5)$ vs $58.4 \%(s=2.7),(P<0.02)$. The average and confidence limits $(\mu \pm$ $\left.t_{0.05} s / \sqrt{n}\right)$ of oil energy values were calculated from individual energy balances obtained with the 2 diets: $M E=19.3 \pm 9.7$ $M J, k l=79.3 \pm 17.7 \%, N E=15.8 \pm 4.7 \mathrm{MJ}$ NEL or $2.22 \pm 0.67$ feed unit for lactation (UFL)/kg.

The mean $M E$ and $N E$ values of rapeseed oil were low, due to the poor digestibility of lipids. This latter resulted from a large excretion of unsaponifiable lipids, which might arise from alterations in the secretion and composition of bile, due to direct infusion of lipids into the duodenum. However, the mean lipid digestibility $(64.7 \%, s=3.6)$ of 6 other fat sources introduced $(970 \mathrm{~g} / \mathrm{d}, s=205$ ) into the diet of lactating cows (Bauchart et al, 1990) would result in an average NE value of $20.1 \mathrm{MJ}$ NEL or 2.83 UFL $/ \mathrm{kg}$ fat.

Bauchart D, Legay-Carmier F, Doreau M (1990) Reprod Nutr Dev suppl 2, 187s

Vermorel M, Sauvant D, Michalet-Doreau B (1986) Bull Tech CRZV Theix 66, 66-73 